\title{
Boredom-like states in mink and their behavioural correlates: a replicate study
}

\section{Article}

Accepted Version

Creative Commons: Attribution-Noncommercial-No Derivative Works 4.0

Meagher, R. K., Campbell, D. L. M. and Mason, G. J. (2017) Boredom-like states in mink and their behavioural correlates: a replicate study. Applied Animal Behaviour Science, 197. pp. 112-119. ISSN 0168-1591 doi: https://doi.org/10.1016/j.applanim.2017.08.001 Available at https://centaur.reading.ac.uk/72054/

It is advisable to refer to the publisher's version if you intend to cite from the work. See Guidance on citing.

Published version at: https://doi.org/10.1016/j.applanim.2017.08.001

To link to this article DOI: http://dx.doi.org/10.1016/j.applanim.2017.08.001

Publisher: Elsevier

All outputs in CentAUR are protected by Intellectual Property Rights law, including copyright law. Copyright and IPR is retained by the creators or other copyright holders. Terms and conditions for use of this material are defined in the End User Agreement.

\section{www.reading.ac.uk/centaur}

\section{CentAUR}

Central Archive at the University of Reading 
Reading's research outputs online 


\section{correlates: a replicate study}

Rebecca K. Meagher ${ }^{1 *}$, Dana L.M. Campbell², Georgia J. Mason

${ }^{1}$ Present address: School of Agriculture, Policy \& Development, University of Reading Whiteknights, PO Box 237, Reading, Berkshire, UK, RG6 6AR

2 Present address: CSIRO, Agriculture and Food, Armidale, NSW 2350, Australia

Abstract

Scientists and laypeople have long expressed concern that animals in non-enriched,

14 unchanging environments might experience boredom. However, this had attracted little

15 empirical study: the state is difficult to assess without verbal self-reports, and spontaneous

16 behavioural signs of boredom can vary in humans, making it hard to identify signs likely to be

17 valid in other species. We operationally define boredom as a negative state that causes an

18 increased, generalised interest in diverse stimuli. Previously, we demonstrated that this state

19 existed in mink housed in non-enriched cages, compared to those in preferred, stress-reducing

20 enriched enclosures; and that this heightened interest in stimuli positively correlated with time spent lying still but awake, while negatively correlating with locomotor stereotypic behaviour.

22 However, these results needed replication. The current study tested for the same effects, in a 
23 new cohort of 20 male mink, by presenting 11 stimuli ranging from those predicted to typically

24 be aversive (e.g. predator cues) to those predicted to be rewarding (e.g. food rewards; moving

25 objects to chase). Where housing treatments differed, non-enriched mink were again more

26 interested in the stimuli presented, spending longer oriented towards and in contact with them

27 (e.g. for aversive stimuli: $F_{1,9}=6.27, p=0.034$ and $F_{1,9}=8.24, p=0.019$, respectively). Lying still but

28 awake again correlated with interest in the stimuli (shorter latencies to contact rewarding

29 stimuli: $F_{1,17}=3.70, p=0.036$; in enriched mink only, more time oriented to and in contact with all

30 stimuli: $F_{1,8}=9.49, p=0.015$ and $\left.F_{1,8}=15.9, p=0.004\right)$. In contrast, the previous correlations with

31 stereotypic behaviour were not replicated. We therefore conclude that mink housed in non-

32 enriched cages likely experience boredom-like states, and that time spent lying still while awake

33 could potentially be used as a cage-side indicator of these states. We also suggest how future

34 researchers might address further fundamental and practical questions about animal boredom,

35 in mink and other species.

36 Keywords: sensation-seeking; emotional states; Neovison vison; animal welfare; inactivity;

37 environmental enrichment

\section{Introduction}

Boredom has long been believed to be a widespread problem in captive animals housed

41 in environments that offer little variety or complexity (see e.g. Manteuffel et al., 2009; Wood-

42 Gush and Beilharz, 1983). If true, this would be a major concern for welfare. Boredom is, by

43 definition, aversive, having commonly been defined as a negative subjective state resulting from

44 environments that provide too little stimulation or variety to satisfy psychological needs (e.g. 
45 Berlyne, 1960; Burn, 2017; Kirkden, 2000); see Eastwood et al., 2012 for broader definitions

46 from different theoretical perspectives). Eastwood and colleagues (2012) wrote that "to be

47 bored... is to be in a state of longing for activity but unaware of what it is that one desires and to

48 look to the world to solve the impasse." In humans, prolonged experience of this feeling can be

49 seriously detrimental to well-being: boredom correlates with depression and anxiety (e.g.

50 LePera, 2011; Sommers and Vodanovich, 2000) and even predicts elevated mortality rates

51 (Britton and Shipley, 2010; Maltsberger et al., 2000). It can also motivate risky behaviours such

52 as recreational drug use and perhaps deliberate self-harm, as bored people seek stimulation

53 (Chapman et al., 2006; Samuels and Samuels, 1974; Wiesbeck et al., 1996). Similarly, boredom

54 has sometimes been blamed for problem behaviour in animals, including stereotypic behaviour

55 in many species (Kiley-Worthington, 1977; Wemelsfelder, 1993) and excessive salt-licking in

56 horses (Krzak et al., 1991). However, boredom is difficult to assess in animals because its

57 symptoms in humans are variable, ranging from inactivity to restlessness and stereotypic

58 behaviour (reviewed by Berlyne, 1960; Burn, 2017; Harris, 2000), making it hard to identify

59 spontaneous behaviour patterns that will reliably and validly indicate boredom in diverse

60 species.

61 An operational definition of boredom is needed in order to validate such possible

62 indicators in non-human animals. We have therefore operationalized boredom as a negative

63 state that (a) is particularly manifest in sub-optimal barren housing (to capture the aversive

64 attributes of this state, and its relation to under-stimulation), and (b) causes hyper-

65 responsiveness to stimuli (to capture the way that enhanced motivation to obtain stimulation

66 should be a defining characteristic) (Meagher and Mason, 2012). Working with American mink, 
67 Neovison vison, we then compared subjects living in non-enriched housing to mink housed in

68 more complex, variable enriched cages that improved their welfare. We demonstrated that

69 when presented in situ with diverse stimuli, ranging from pleasant to mildly aversive or

70 frightening, the non-enriched mink did indeed exhibit more interest in them, generally

71 investigating them faster and for longer (Meagher and Mason, 2012). In this first study, there

72 were also hints of a relationship between this core symptom of a boredom-like state and time

73 spent performing two types of behaviour when undisturbed in the home cage. Time spent lying

74 inactive despite being awake (i.e. inert, but with eyes open) tended to correlate positively with

75 interest in the stimuli presented, identifying this form of inactivity as a potential symptom of

76 boredom. Time spent performing locomotor, head and whole-body stereotypic behaviours

77 (hereafter referred to simply as 'loco' stereotypies following (Diez-Leon et al., 2016) by contrast,

78 tended to correlate negatively with interest in the stimuli, a finding that could cautiously be

79 interpreted as support for the hypothesis that stereotypic behaviour may alleviate boredom

80 (Kiley-Worthington, 1977). However, for both behaviour patterns, the relationships were not

81 consistent across all measures and treatments.

82 We therefore conducted the current experiment to test whether the previous findings,

83 including these relationships between interest in stimuli and lying still but awake and locomotor

84 stereotypic behaviour, could be replicated. If such behaviours are reliably associated with

85 boredom-like states, these could be very useful indicators for practical welfare assessments

86 (when experimentally assessing animals' responses to multiple probe stimuli, our primary index

87 of boredom, would be highly impractical). The protocol was the same as that for the original

88 experiment, but some of the specific stimuli employed were changed in order to increase the 
89 generalisability of the results. Some further differences from the original study likely arose from

90 the fact that this new work was conducted opportunistically at the 'tail end' of research on our

91 subjects' sexual behaviour: an issue we return to in the Discussion.

92

93 2. Methods

$94 \quad 2.1$ Subjects and housing

95

The subjects were 20 male mink of the Black colour-type (strain): of these, there were

97 nine pairs of brothers, the two siblings of each pair being differentially housed (see below). They

98 had just reached sexual maturity, being 9 to 11 months old during the experimental period.

99 They were housed individually indoors at the Michigan State University research farm

100 (Michigan, USA), in $75(\mathrm{~L}) \times 60(\mathrm{~W}) \times 45(\mathrm{H}) \mathrm{cm}$ wire-mesh cages with external wooden nest

101 boxes. These conditions are relatively standard for countries in which enrichment is not

102 required. Mink were fed once per day with a meat-based paste, and had ad libitum access to

103 drinking water. The research was approved by the University of Guelph Animal Care Committee,

104 and by Michigan State University's Institutional Animal Care and Use Committee.

105 One mink from each sibling pair, the subject randomly allocated to the non-enriched

106 (NE) treatment, was limited to the single cage. The other mink (randomly allocated to the

107 Enriched group; E) were raised and housed with additional access to an enriched compartment

108 of twice the width, reached via a wire mesh "bridge". This additional cage contained a channel

109 of running water, and new structural or manipulable objects added each month (see Dallaire et

110 al., 2012; Díez-León and Mason, 2016 for more details on these cages). This enrichment 
111 treatment had been previously demonstrated to reduce stress and to be valued by mink

112 (Dallaire et al., 2012; Meagher et al., 2013). Enriched and non-enriched cages were evenly

113 distributed throughout the room following a pattern of NE, E, E, NE. All mink had been in their

114 respective housing conditions from the time they were approximately three months of age, with

115 the exception -- for 16 of the 20 males -- of a few hours per day during the mating season (ten

116 days in March during which they were given four to five mating opportunities (as part of a

117 project on sexual behaviour), ending just before we began to present them with beginning of

118 the interest in stimuli as described below. During this mating period, the enriched mink of that

119 group were restricted to their home cages (i.e. to housing identical to that of their non-enriched

120 brothers).

121

1232.2 Spontaneous behaviour

124

125 Baseline behaviour was observed through modified instantaneous sampling, as standard

126 for our research group (e.g. as described in Meagher and Mason, 2012). The observations were

127 performed by a single observer over 10 days in December to February, from 8:30 to 14:00 each

128 day; each mink was observed every $15 \mathrm{~s}$ for 4 min twice within this period, for a total of 340

129 observations across all days. Mink were fed at approximately 15:00. As in the previous study,

130 the behaviours of interest were 'loco' stereotypy (e.g. pacing or head-twirling; defined as three

131 consecutive repetitions of a movement or series of movements) and lying still but awake (i.e.

132 with the eyes open and visible to the observer). These data were thus collected two to three 
133 months prior to our tests for interest in stimuli, but individual differences in mink behaviour are

134 typically very stable, even over far longer time periods than this (Dallaire et al., 2012; Hansen et

135 al., 2010; Mason, 1993).

136

2.3 Tests for interest in stimuli

138

A series of 14 behavioural tests per mink were conducted over eight days in late March

140 and early April, after the mating period had ended. The order of these tests and details of the

141 stimuli used are provided in Table 1. Stimuli were categorised $a$ priori as likely aversive, likely

142 rewarding, or ambiguous (/neutral) based on their biological / ecological relevance (or lack

143 thereof for ambiguous stimuli). Most stimuli that had appeared to be appropriate

144 representatives of the categories in the original experiment were used again (e.g. the handling

145 glove, as the most clearly aversive based on fear scores, high latency to contact and low time in

146 contact; and the moving brush, as eliciting extremely high levels of interest; Meagher \& Mason

147 2012), while a previous 'ambiguous' (neutral) stimulus with the shortest latency to contact (the

148 maraca) was eliminated because it may have been rewarding to the mink. Additional stimuli

149 thought a priori to be rewarding based on biological relevance or common usage (pheasant

150 scent as a prey-related cue, and a commercial lure used by trappers to attract mink) were added

151 to improve representation of that category. The predator urine for aversive stimuli (cf. e.g.

152 Apfelbach et al., 2005) was provided by the Detroit Zoo (Royal Oak, Michigan), with urine of two

153 species selected from four available after a brief pilot test on mink not used in the study. All

154 stimuli were equally novel to the mink in both treatments. 
Three of the tests measured consumption of food rewards, in which the proportion of

156 treats offered that were consumed within 20 minutes was assessed for all mink simultaneously.

157 The remaining 11 tests assessed investigatory behaviour. In these, a single stimulus was

158 presented to the mink by placing it on top of or in front of the cage for $5 \mathrm{~min}$. After placing the

159 object, the observer (RKM) stepped away from the cage and remained stationary, with the

160 exception of the glove and toothbrush, in which she remained stationary directly in front of the

161 cage with the gloved hand extended (for more details on this protocol, see Meagher et al.,

162 2011). Mink were tested consecutively within rows of cages. These tests alternated between

163 stimuli that had been categorised as aversive, rewarding, or ambiguous. Tests began at 8:30 and

164 13:30 each day, but no afternoon test was given if an aversive stimulus had been presented in

165 the morning, to allow the mink time to recover. A test only began when the subject mink was in

166 the home compartment; enriched mink were encouraged to return there if necessary by

167 tapping on the cage and/or dragging a cable tie along the top of the cage for a few seconds at a

168 time, but were skipped if they failed to return within $10 \mathrm{~min}$ ( $n=2$ over all the 212 tests

169 conducted). If a mink slept for more than 3 min during an attempted test, that animal was

170 skipped and given another opportunity after all other mink had been tested; if they failed to

171 awaken a second time, they were excluded from the analysis for that test ( $n=11$ of the 212

172 tests).

173 The latency to make contact with each stimulus, total time in contact with it, and time

174 with the head oriented towards it, with eyes open, were recorded as measures of interest in the

175 stimuli. If the mink never made contact, the maximum latency was assigned. Contact was

176 defined as touching the item with the muzzle or front paws. In addition, as in our previous work, 
177 fear was scored live by the presence of four behaviours: retreats (confirmed from video where

178 necessary), alternation between retreat and approach, screams (fear vocalisations), and

179 spraying from the scent glands. Latencies were recorded live, while contact was recorded from

180 video by an observer blind to the hypothesis under test, and orientation was recorded using

181 both methods. Interobserver reliability was therefore checked against live observations for

182 orientation. Unfortunately, the videos were lost before contact time could be assessed by a

183 second observer. Where there were major discrepancies (revealed by outliers in the rank

184 correlation data) for orientation, orientation and contact values for that individual for that test

185 were excluded from the analysis.

186

\subsection{Statistical analysis}

To test whether the "aversive" stimuli were in fact more frightening than the others to

190 these mink, we averaged fear scores for each individual within stimulus type, then ran Wilcoxon

191 signed rank tests to compare means for the aversive stimuli to those in each of the other two

192 categories. We also summed fear scores across individuals to examine the pattern across

193 individual stimuli. A Welch's ANOVA was used to compare mean latencies across stimulus types,

194 because variances were unequal.

195 To assess housing effects on responsiveness to stimuli, the data were analysed using

196 MANOVAs (multivariate analysis of variance) for repeated measures for each dependent

197 variable (latency, orientation, and contact duration and proportion of food treats consumed).

198 These models were run both for all stimuli together, and then, to replicate our previous work, 
199 split by stimulus type (rewarding, ambiguous and aversive). Residuals were visually inspected

200 for normality and homogeneity of variance. Latency values were log-transformed for all

201 analyses to correct non-normality of the data. Housing effects on spontaneous behaviour were

202 assessed using a Wilcoxon rank-sum test for lying alert, due to non-normality, and a Welch's

203 ANOVA for locomotor stereotypy, which had unequal variances.

204 To assess relationships between responsiveness to stimuli and the two spontaneous

205 behaviour patterns of interest, we first obtained least squares means by individual for each

206 dependent variable in general linear models, with individual nested in family as a random factor

207 and stimulus number as a fixed factor (to control for order effects). Latency values were log-

208 transformed to improve normality, as above, and contact duration values were square root-

209 transformed. This approach provided a single index of responsiveness for each measure

210 (latency, orientation, and contact) across all stimuli tested, for each individual mink. These

211 indices could then be regressed against spontaneous behaviour: relationships that were

212 assessed using general linear models, controlling for treatment and its interaction with the

213 behaviour of interest (the interaction term being removed if its $p$-value was greater than 0.25 ;

214 Quinn and Keough, 2002).

215 One-tailed $p$-values were used because the predictions were directional, since this was a

216 study explicitly trying to replicate previous findings. All analyses were conducted in JMP 12 (SAS

217 Institute Inc., North Carolina, USA).

218

219 3. Results

$220 \quad 3.1$ Validation of stimulus categories 
As predicted, latencies differed between stimulus types $\left(F_{2,32}=3.79, p=0.033\right)$, with

222 rewarding stimuli having the shortest latencies and aversive the longest ones (back-transformed

223 means of least square means, with interquartile ranges: $1.91 \mathrm{~s}$ [1.03-3.83 s] vs. $5.06 \mathrm{~s}$ [3.83-8.06

224 s]). Latencies by individual stimulus are presented in Table 1. Similarly, time in contact was

225 highest for rewarding stimuli (back-transformed means: 175 s [IQR: 81-278 s] vs. 87s [21-139 s]

226 and $89 \mathrm{~s}[38-152 \mathrm{~s}]$ and for ambiguous and aversive respectively; Welch's ANOVA $F_{2,36}=16.0$,

$227 \quad p<0.001)$

228 Specific indicators of fear were very rarely observed, as is apparent from the summed

229 scores for all individuals in Table 1. Fifteen of twenty mink never exhibited any of these

230 indicators, compared to just 3 of 29 mink or 2 of 14 males in the original experiment (Fisher's

$231 p<0.0001$ and $p=0.001$, respectively). Furthermore, only two of the four aversive stimuli, along

232 with the first stimulus presented (which was categorized a priori as rewarding), elicited fear

233 behaviour from any individuals. Matched pairs tests did, however, show a tendency for these

234 scores to be higher for aversive than for rewarding or ambiguous stimuli (one-sided $p=0.063$ ).

$236 \quad 3.2$ Housing effects on interest in stimuli

237 The effects of housing on minks' responses to the stimuli presented are summarised in

238 Table 2 (where they are shown in comparison with the results from the original experiment). In

239 brief, where there were treatment effects here, non-enriched mink again explored the stimuli

240 more than enriched mink did (see Fig. 1). This was true for time in contact, when all stimuli were

241 included in the analysis (contact: $F_{1,4}=22.8, p=0.004$ ), but for orientation, there was an

242 interaction with test, i.e. the stimulus used $\left(F_{9.6,48.1}=2.50, p=0.018\right.$; see Table 3 for treatment 
243 means by stimulus). Broken down by stimulus type, both of these measures were higher in non-

244 enriched mink for aversive stimuli $\left(F_{1,8}=4.12, p=0.038\right.$ and $\left.F_{1,8}=6.97, p=0.015\right)$, and there was

245 also a non-significant tendency in this direction for rewarding stimuli (orientation: $F_{1,9}=4.85$,

$246 p=0.055$; contact: $\left.F_{1,8}=4.84, p=0.059\right)$. For ambiguous stimuli, however, there were further

247 interactions with the individual stimuli for both orientation $\left(F_{2.8,19.9}=4.19, p=0.020\right)$ and contact

$248\left(F_{2.5,17.2}=4.72, p=0.018\right)$, which appeared to be due to responses to a single stimulus, the candle,

249 not being numerically higher in non-enriched mink as they were for the other ambiguous stimuli

250 (see Table 3). There were no treatment effects on latencies to make contact or on food reward

251 consumption, in contrast with the original experiment.

252

253

\subsection{Behavioural correlates of interest in stimuli}

Locomotor stereotypic behaviour was, as expected, reduced by enrichment (mean $0.9 \%$

255 vs. $7.0 \%$ of observations, $\left.F_{1,9.5}=5.39, p=0.044\right)$; and 9 of $10 \mathrm{NE}$ mink were seen performing this

256 behaviour vs. 4 of $10 \mathrm{E}$ mink. However, unlike in our original study, time spent lying still but

257 awake was not affected by housing treatment (median $1.0 \%$ of observations in NE vs. $0.6 \%$ in $E$,

$258 p>0.10 ; 8$ of $10 \mathrm{NE}$ mink performed the behaviour vs. 6 of $10 \mathrm{E}$ mink). Despite this, time spent

259 lying still but awake did show some of the expected relationships with stimulus exploration, as

260 outlined below.

261 In the analyses with all stimuli, time spent lying still but awake did not correlate with

262 latency to touch. However, for time oriented to all stimuli, there was an interaction with

263 housing treatment $\left(\mathrm{R}^{2}=0.43, \mathrm{~F}_{1,16}=5.47, p=0.033\right.$; Fig. 2$)$; and in the enriched treatment only,

264 lying awake correlated positively with time oriented to stimuli $\left(F_{1,8}=9.49, p=0.008\right)$. The same 
265 was true for time in contact with stimuli $\left(R^{2}=0.53\right.$, interaction: $F_{1,19}=7.54, p=0.014$; Fig. 3 ;

266 relationship in enriched mink: $\left.F_{1,8}=15.9, p=0.002\right)$. When stimuli were split by sub-type, time

267 spent lying still but awake also correlated negatively with latency to touch, albeit for rewarding

268 stimuli only $\left(R^{2}=0.22, F_{1,17}=3.70, p=0.036\right)$. In enriched mink, lying awake also correlated

269 positively with time oriented to and in contact with aversive stimuli (orientation: $R^{2}=0.43$,

$270 \mathrm{~F}_{1,8}=6.06, p=0.016$; contact: $\left.\mathrm{R}^{2}=0.67, \mathrm{~F}_{1,8}=16.6, p=0.002\right)$ and with contact with ambiguous

271 stimuli $\left(\mathrm{R}^{2}=0.43, \mathrm{~F}_{1,8}=5.95, p=0.020\right)$. 'Loco' stereotypic behaviour, in contrast, did not correlate

272 with any response to the stimuli overall nor within any category $(p>0.10)$. The pattern of results

273 across all measures is summarised in Table 4 (where they are also contrasted with the original

274 study's findings).

275

276 4. Discussion

277 As in our previous work, compared to enriched mink, non-enriched mink showed signs of

278 exaggerated interest in stimuli that were consistent with boredom-like states. There was also

279 some evidence that, as before, the behaviour of lying still despite being awake, was a correlate

280 of this state. Not everything was similar between the original and replicate experiment

281 however: the current mink showed far fewer signs of fear, even when presented with stimuli

282 that should have been threatening; and non-enriched animals now did not spend more time

283 lying awake than enriched ones. The precise patterns of effects across stimulus sub-types also

284 differed (for example, non-enriched mink now did not consume more food treats than enriched

285 mink). In some instances, these differences may have reflected our use of a slightly different set

286 of test stimuli; a degree of uncertainty in both studies in the assignment of stimuli to the 
rewarding, ambiguous, and aversive categories; and/or low sample sizes for the MANOVAs due

288 to some missing data in the replicate study. However, we also suspect they reflect differences in

289 timing: because the replicate study was conducted just a few days after a 10-day long mating

290 period in which most males, regardless of their rearing and housing conditions, were given

291 regular access to salient positive stimuli (females) and opportunities to perform highly

292 motivated, time-consuming activities (courtship and mating). This could well have reduced

293 boredom and, reduced any difference between housing treatments. We recognise that this

294 timing was non-ideal, but it was unavoidable practically (as we were using a narrow window of

295 opportunity available while facilities and research staff time were available).Despite this, we did

296 successfully replicate the original finding of increased exploratory behaviour by mink in non-

297 enriched housing.

298 This consistent finding of increased exploratory behaviour in mink living in non-enriched

299 environments has interesting implications. First, it confirms that assessing non-specific

300 exploration in a familiar environment is a worthwhile way to assess boredom-like states in

301 barren housing, and so potentially useful for testing boredom-related hypotheses in mink and

302 other species (including, for instance, fascinating new hypotheses about how boredom might

303 co-vary with changes in time perception: Burn 2017). Second, this finding raises fundamental

304 functional questions about why animals might have non-specific needs for stimulation or

305 arousal. This includes whether maintaining moderate arousal levels is important for brain

306 development in early life or promotes learning, as suggested by the Yerkes-Dodson law (see e.g.

307 Burn, 2017). Third, in terms of practical on-farm welfare, it also suggests that the practice in

308 some Scandinavian countries of selectively breeding farmed mink for exploratory responses in 
309 temperament tests (e.g. Malmkvist and Hansen, 2001) may not always be good for welfare if

310 selection relies heavily on the response to an unfamiliar object (a stick used in one of the

311 temperament tests). The common alternatives to exploration are aggressive or fearful

312 responses, and some exploratory behaviour is indeed likely preferable to fear, but our data

313 suggest that the tests as used may perhaps lead to the accidental selection for boredom-

314 proneness. This hypothesis now needs further research: whether non-enriched mink showing

315 the most extreme levels of interest in stimulation have the poorest welfare needs investigation,

316 for example by looking at markers of chronic stress after long-term housing in these conditions.

317 A related issue is that our finding seems, at least superficially, at odds with much

318 research on enrichment that reveals enriched animals to be bolder (see e.g. Jones and

319 Waddington, 1992 on chicks and Meagher et al., 2014 on mink). We suggest that this may be

320 because fear and timidity are biologically dissociable from neophilia (see e.g. Mettke-Hoffman

321 et al., 2002; Réale et al., 2007): a distinction that might help future researchers interested

322 specifically in boredom. Boredom is thus be easiest to detect with novel stimuli which best

323 distinguish explorativeness from boldness, and so care should be taken to avoid the use of

324 stimuli perceived as too similar to those experienced by subjects in enriched conditions, since

325 habituation may be generalized. Boredom may also be easiest to assess in populations with

326 relatively low levels of fear, such as this one, since high levels of fear are likely to override other

327 motivations and prevent exploration. This last issue could explain why the literature currently

328 shows conflicting evidence on the effects of enriched housing on exploratory behaviour, since

329 some research that has suggested that enrichment can increase exploration (e.g. Acklin and

330 Gault, 2015; Renner, 1987), the non-enriched treatments used might well have increased 
331 baseline anxiety (e.g. isolation combined with barren housing), and the tests of exploration

332 were conducted in novel environments. By contrast, non-enriched pigs given novel objects in

333 their home environments for longer periods of time show increased exploration relative to

334 enriched-housed animals (e.g. Bracke and Spoolder, 2008; Stolba and Wood-Gush, 1980).

335 The specific stimuli used may thus be important in distinguishing between underlying

336 states, in terms of their valence and salience. Table 3 provides information on responses to the

337 stimuli we have employed for mink to date. Across the two studies, the moving stimulus

338 (toothbrush) and air puff attracted the most interest (indicated by prolonged orientation and

339 contact), and the air as well as the glove elicited fear responses, making these the most clearly

340 aversive stimuli. The first stimulus presented, whether this had been categorized as

341 "ambiguous" (bottle, original study) or "rewarding" (pheasant scent, replication) also elicited

342 fear. Scents with no apparent biological relevance (vanilla and peppermint), meanwhile,

343 attracted little attention. For future work in mustelids, we therefore recommend "chaseable"

344 stimuli as likely rewarding, and air puffs and handling gloves as aversive. In terms of usefulness

345 in assessing boredom, the stimuli attracting moderate interest seemed to be the most

346 successful, as indicated by the largest housing effects on orientation and contact times (the

347 pheasant scent, followed by the predator scents and plastic bottle, in the current study; and the

348 female faeces and candle in the original study). Frightening (glove and air puff) and highly

349 attractive (moving toothbrush) stimuli, by contrast, elicited high exploration, that was more

350 universal across treatments. Thus, boredom-like elevated interest appears most pronounced for

351 mildly rewarding and neutral/ambiguous stimuli. We therefore recommend that future research 
352 of this kind in other species begin with pilot testing to determine the typical valence of the

353 novel stimuli on a separate group of subjects in both enriched and non-enriched conditions.

354 With respect to the behavioural correlates of boredom-like responses, one of the two

355 findings from the original experiment was replicated: the positive relationship with lying still but

356 awake. By contrast, the previous relationships with loco stereotypic behaviour were not

357 apparent in this cohort, suggesting that stereotypic behaviour is not reliably linked to boredom

358 in farmed mink. The confirmed link between boredom-like states and awake forms of inactivity,

359 in which animals lie still despite being open-eyed and alert, adds to growing evidence that some

360 forms of inactivity indicate poor animal welfare (Fureix and Meagher, 2015). It is also somewhat

361 consistent with the human boredom literature; behavioural lethargy is considered a common

362 symptom, although to our knowledge, to date no studies have yet investigated phenotypic

363 subtypes of inactivity in humans that correlate with boredom. Furthermore, theoreticians have

364 argued that states of 'limbo' are possible in animals, in which their physiological needs are met

365 but they are left with time they cannot fill with motivated behaviours (McFarland, 1989). This

366 may produce negatively-valenced states of either boredom or depression depending on the

367 individual and/or the duration of time spent in these conditions (cf. Wemelsfelder, 1990). Our

368 findings complement data on the awake inactivity associated with poor welfare in horses and

369 mice, although here 'standing doing nothing' is hypothesised to reflect depression-like states,

370 and in horses is linked with reduced rather than increased responsiveness to stimuli (Fureix et

371 al., 2012; Fureix et al., 2016). Furthermore, "idle standing" is also sometimes reported as an

372 undesirable occurrence in species such as dairy cattle (related to sickness, social competition, or

373 uncomfortable environments: Fogsgaard et al., 2012; Huzzey et al., 2006; Rushen et al., 2007), 
374 although not yet attributed to any particular psychological state. The states underlying these

375 other forms of awake inactivity thus now need to be investigated in a range of species.

376 Lying still but awake is, however, by no means a perfect indicator of boredom in mink. If

377 used simplistically as a boredom indicator, it clearly would be prone to false negatives or Type II

378 errors, since some individuals who were not observed performing this behaviour were still very

379 interested in stimuli (especially in the NE mink: a crucial drawback of this measure if it is to be

380 used on farms, for animals whose housing is more like our NE cages than our E conditions).

381 Furthermore, in this current cohort, absolute levels of lying awake were also not significantly

382 elevated in NE housing, despite these animals' elevated levels of boredom-like exploration: a

383 difference from the original study indicating a group-level dissociation here between these two

384 aspects of behaviour. However, at an individual level, lying awake in both studies was rather

385 consistently correlated with interest in stimuli in the enriched-housed mink. If lying awake is

386 confirmed not to correlate with interest in stimuli in mink housed in standard farm conditions,

387 more research is needed to determine how such mink typically manifest boredom-like states.

388 Why some correlations with spontaneous behaviour were seen only within the enriched

389 treatment in both experiments remains an outstanding question. While NE mink were almost

390 universally highly exploratory in the original experiment, leaving less possibility of detecting

391 correlations due to ceiling effects, in this replicate study variation was not higher in enriched

392 than non-enriched mink for all measures of interest in stimuli. To explore this puzzle further, we

393 recommend now replicating this study once again, but better timed to avoid any potential after-

394 effects of the mating season. 
396 behaviours of mink thus appears difficult, despite these intriguing relationships with awake

397 inactivity, and since tests such as those used here are time-consuming and difficult to conduct in

398 commercial settings, we believe that such future work could benefit from now also including

399 qualitative behaviour assessments (QBA). The adjective "bored" is already included in some

400 QBA protocols (e.g. Brscic et al., 2009 for veal calves), and has adequate inter-observer

401 reliability in some species (Forkman and Keeling, 2009), although the label has not yet been

402 validated. In factor analysis of these QBA data, it has also been linked to descriptors of activity

403 levels (Brscic et al. 2009: negatively loaded in the same factor that included "active" and "lively"

404 among positive loadings). We suggest that measures of elevated interest in stimuli as used here

405 could be suitable for such a validation of these QBA labels. Reciprocally, QBA could then emerge

406 as a useful practical way of identifying boredom in mink (since potentially less time-consuming

407 than exploration-related tests), especially if it proved to show greater sensitivity and less

408 proneness to false negatives than the measures of spontaneous lying awake behaviour we have 409 used to date.

\section{5. Conclusions}

412 This study confirms our previous findings that long-term housing in non-enriched

413 conditions induces increased interest in a range of stimuli in farmed mink, consistent with the

414 presence of boredom-like states. It also broadly replicates the finding that spending more time

415 lying still but awake is positively correlated with this state, at least among mink in enriched

416 housing. More research is still needed to understand the conditions under which this form of 
417 inactivity could be used as a more reliable indicator of boredom, and to identify other

418 symptoms that could be used in combination (perhaps as part of a QBA assessment). In the

419 meantime, our results confirm that assessing the degree of responsiveness to a range of stimuli

420 can be used to reveal boredom-like states in animals in non-enriched housing, with potential

421 implications not just for mink, but for other species as well.

\section{Acknowledgements}

We would like to thank Michelle Tagliafierro, Kammy Punniamoorthy, Kaitlin Bahlmann,

426 Meister of the Detroit Zoo. NSERC (grant no. 145607319) and the Campbell Centre for the Study

427 of Animal Welfare at the University of Guelph provided the research funding.

\section{References}

430 Acklin, C.J., Gault, R.A., 2015. Effects of natural enrichment materials on stress, memory and 431 exploratory behavior in mice. Lab Anim. 44, 262-267.

432 Apfelbach, R., Blanchard, C.D., Blanchard, R.J., Hayes, R.A., McGregor, I.S., 2005. The effects of 433 predator odors in mammalian prey species: A review of field and laboratory studies. Neurosci. 434 Biobehav. Rev. 29, 1123-1144 doi: 10.1016/j.neubiorev.2005.05.005.

435 Berlyne, D.E., 1960. Conflict, Arousal, and Curiosity. McGraw-Hill, New York.

436 Bracke, M.B.M., Spoolder, H.A.M., 2008. Novel object test can detect marginal differences in 437 environmental enrichment in pigs. Appl. Anim. Behav. Sci. 109, 39-48 doi:

438 10.1016/j.applanim.2007.01.014.

439 Britton, A., Shipley, M.J., 2010. Bored to death? Int. J. Epidemiol. 39, 370-371 doi:

$440 \quad 10.1093 / \mathrm{ije} / \mathrm{dyp} 404$. 
441 Brscic, M., Wemelsfelder, F., Tessitore, E., Gottardol, F., Cozzi, G., Van Reenen, C.G., 2009.

442 Welfare assessment: correlations and integration between a Qualitative Behavioural

443 Assessment and a clinical/health protocol applied in veal calves farms. Italian Journal of Animal

444 Science 8, 601-603.

445 Burn, C.C., 2017. Bestial boredom: a biological perspective on animal boredom and suggestions 446 for its scientific investigation. Anim. Behav. 130, 141-151 doi:

447 https://doi.org/10.1016/j.anbehav.2017.06.006.

448 Chapman, A.L., Gratz, K.L., Brown, M.Z., 2006. Solving the puzzle of deliberate self-harm: The 449 experiential avoidance model. Behav. Res. Ther. 44, 371-394 doi:

450 http://dx.doi.org/10.1016/j.brat.2005.03.005.

451 Dallaire, J.A., Meagher, M.K., Mason, G.J., 2012. Individual differences in stereotypic behaviour 452 453 predict individual differences in the nature and degree of enrichment use in caged American mink. Appl Anim Behav Sci 142:1, 98-108.

454 Díez-León, M., Mason, G., 2016. Effects of environmental enrichment and stereotypic behavior 455 on maternal behavior and infant viability in a model carnivore, the American mink (Neovison 456 vison). Zoo Biol. 35, 19-28.

457 Diez-León, M., Bursian, S., Galicia, D., Napolitano, A., Palme, R., Mason, G., 2016.

458 Environmentally enriching American mink (Neovison vison) increases lymphoid organ weight 459 and skeletal symmetry, and reveals differences between two sub-types of stereotypic 460 behaviour. Appl. Anim. Behav. Sci. 177, 59-69 doi: 10.1016/j.applanim.2015.12.002.

461 Eastwood, J.D., Frischen, A., Fenske, M.J., Smilek, D., 2012. The Unengaged Mind. Perspectives 462 on Psychological Science 7, 482-495 doi: 10.1177/1745691612456044.

463 Fogsgaard, K.K., Rontved, C.M., Sorensen, P., Herskin, M.S., 2012. Sickness behavior in dairy 464 cows during Escherichia coli mastitis. J. Dairy Sci. 95, 630-638 doi: 10.3168/jds.2011-4350.

465 Forkman, B., Keeling, L.J., 2009. Assessment of animal welfare measures for dairy cattle, beef 466 bulls and veal calves. Welfare Quality Reports 11, 1-314.

467 Fureix, C., Jego, P., Henry, S., Lansade, L., Hausberger, M., 2012. Towards an Ethological Animal 468 Model of Depression? A Study on Horses. PLoS ONE 7, e39280.

469 Fureix, C., Meagher, R.K., 2015. What can inactivity (in its various forms) reveal about affective 470 states in non-human animals? A review. Appl. Anim. Behav. Sci. 171, 8-24 doi:

$471 \quad$ 10.1016/j.applanim.2015.08.036. 
472 Fureix, C., Walker, M., Harper, L., Reynolds, K., Saldivia-Woo, A., Mason, G., 2016. Stereotypic

473 behaviour in standard non-enriched cages is an alternative to depression-like responses in

474 C57BL/6 mice. Behav. Brain Res. 305, 186-190 doi: http://dx.doi.org/10.1016/j.bbr.2016.02.005.

475 Hansen, B.K., Jeppesen, L.L., Berg, P., 2010. Stereotypic behaviour in farm mink (Neovison vison)

476 can be reduced by selection. J. Anim. Breed. Genet. 127, 64-73 doi: 10.1111/j.1439-

477 0388.2009.00814.x.

478 Harris, M.B., 2000. Correlates and characteristics of boredom proneness and boredom. J. Appl.

479 Soc. Psychol. 30, 576-598 doi: 10.1111/j.1559-1816.2000.tb02497.x.

480 Huzzey, J., DeVries, T., Valois, P., von Keyserlingk, M., 2006. Stocking density and feed barrier

481 design affect the feeding and social behavior of dairy cattle. J. Dairy Sci. 89, 126-133.

482 Jones, R.B., Waddington, D., 1992. Modification of fear in domestic chicks, Gallus gallus

483 domesticus, via regular handling and early environmental enrichment. Anim. Behav. 43, 1021-

4841033.

485 Kiley-Worthington, M., 1977. Behavioural Problems in Farm Animals. Oriel Press Ltd., 486 Stocksfield, UK.

487 Kirkden, R.D., 2000. Assessing motivational strength and studies of boredom and enrichment in 488 pigs.

489 Krzak, W.E., Gonyou, H.W., Lawrence, L.M., 1991. Wood chewing by stabled horses: diurnal 490 pattern and effects of exercise. 69, 1053-1058 doi: 10.2527/1991.6931053x.

491 LePera, N., 2011. Relationships Between Boredom Proneness, Mindfulness, Anxiety, Depression, 492 and Substance Use. The New School Psychology Bulletin 8, 15-25.

493 Malmkvist, J., Hansen, S.W., 2001. The welfare of farmed mink (Mustela vison) in relation to 494 behavioural selection: A review. Anim. Welfare 10, 41-52.

495 Maltsberger, J., Sakinofsky, I., Jha, A., Maltsberger, J., 2000. Mansur Zaskar: A man almost bored 496 to death. Suicide Life-Threat. Behav. 30, 83-90.

497 Manteuffel, G., Langbein, J., Puppe, B., 2009. From operant teaming to cognitive enrichment in 498 farm animal housing: bases and applicability. Anim. Welfare 18, 87-95.

499 Mason, G.J., 1993. Age and Context Affect the Stereotypies of Caged Mink. Behaviour 127, 191500229.

501 McFarland, D., 1989. Problems of Animal Behaviour. Longman, Harlow, UK. 
502 Meagher, R.K., Campbell, D.L., Dallaire, J.A., Díez-León, M., Palme, R., Mason, G.J., 2013.

503 Sleeping tight or hiding in fright? The welfare implications of different subtypes of inactivity in

504 mink. Appl Anim Behav Sci 144, 138-146.

505 Meagher, R.K., Mason, G.J., 2012. Environmental enrichment reduces signs of boredom in caged 506 mink. PLOS ONE 7:11, e49180.

507 Meagher, R.K., Ahloy Dallaire, J., Campbell, D.L.M., Ross, M., Møller, S.H., Hansen, S.W., Díez-

508 León, M., Palme, R., Mason, G.J., 2014. Benefits of a Ball and Chain: Simple Environmental

509 Enrichments Improve Welfare and Reproductive Success in Farmed American Mink (Neovison

510 vison). PLoS ONE 9, e110589.

511 Meagher, R.K., Duncan, I., Bechard, A., Mason, G.J., 2011. Who's afraid of the big bad glove?

512 Testing for fear and its correlates in mink. Appl. Anim. Behav. Sci. 133, 254-264 doi:

513 10.1016/j.applanim.2011.05.009.

514 Mettke-Hofmann, C., Winkler, H., Leisler, B., 2002. The significance of ecological factors for 515 exploration and neophobia in parrots. Ethology 108, 249-272 doi: 10.1046/j.1439-

516 0310.2002.00773.x.

517 Quinn, G.P., Keough, M.J., 2002. Experimental Design and Data Analysis for Biologists.

518 Cambridge University Press, Cambridge, UK.

519 Réale, D., Reader, S.M., Sol, D., McDougall, P.T., Dingemanse, N.J., 2007. Integrating animal

520 temperament within ecology and evolution. Biological reviews 82, 291-318. doi:10.1111/j.1469-

521 185X.2007.00010.x.

522 Renner, M.J., 1987. Experience-Dependent Changes in Exploratory-Behavior in the Adult-Rat

523 (Rattus-Norvegicus) - overall Activity Level and Interactions with Objects. Journal of

524 Comparative Psychology 101, 94-100.

525 Rushen, J., Haley, D., de Passillé, A.M., 2007. Effect of Softer Flooring in Tie Stalls on Resting 526 Behavior and Leg Injuries of Lactating Cows. J. Dairy Sci. 90, 3647-3651 doi: 10.3168/jds.2006527463.

528 Samuels, D.J., Samuels, M., 1974. Low self-concept as a cause of drug abuse. Journal of Drug 529 Education 4, 421-438.

530 Sommers, J., Vodanovich, S.J., 2000. Boredom proneness: Its relationship to psychological- and 531 physical-health symptoms. J. Clin. Psychol. 56 doi: 10.1002/(SICI)1097-

532 4679(200001)56:13.0.CO;2-Y.

533 Stolba, A., Wood-Gush, D.G.M., 1980. Arousal and Exploration in Growing-Pigs in Different

534 Environments. Applied Animal Ethology 6, 382-383. 
535 Wemelsfelder, F., 1990. Boredom and Laboratory Animal Welfare, in: Rollin, B.E., Kesel, M.L. 536 (Eds.), The Experimental Animal in Biomedical Research. CRC-Press, Boca Raton, Florida, pp.

$537 \quad 243-272$.

538 Wemelsfelder, F., 1993. The concept of animal boredom and its relationship to stereotyped 539 behaviour, in: Lawrence, A.B., Rushen, J. (Eds.), Stereotypic behavior: fundamentals and 540 applications to animal welfare. CAB International, Wallingford, UK, pp. 95-96.

541 Wiesbeck, G., Wodarz, N., Mauerer, C., Thome, J., Jakob, F., Boening, J., 1996. Sensation

542 seeking, alcoholism and dopamine activity. European Psychiatry 11, 87-92 doi:

543 http://dx.doi.org.idpproxy.reading.ac.uk/10.1016/0924-9338(96)84785-7.

544 Wood-Gush, D.G.M., Beilharz, R.G., 1983. The enrichment of a bare environment for animals in 545 confined conditions. Applied Animal Ethology 10, 209-217 doi: 10.1016/0304-3762(83)90142-6. 
549 Table 1. Stimuli for investigatory behaviour and treat consumption tests

\section{Mean latency}

\begin{tabular}{|c|c|c|c|c|}
\hline & & Order & Sum of & to contact (s; \\
\hline Category & Stimulus name & presented & fear scores & $95 \% \mathrm{Cl})^{1}$ \\
\hline Rewarding & Pheasant scent $^{2}$ & 1 & 2 & $2.9(1.1-7.6)$ \\
\hline Ambiguous & "Linen"-scented candle* & 2 & 0 & $7.5(2.6-21.1)$ \\
\hline Aversive & Polar bear urine ${ }^{2}$ & 3 & 0 & $5.7(2.3-13.9)$ \\
\hline Ambiguous & Rope and cloth dog toy & 4 & 0 & $1.5(0.6-3.4)$ \\
\hline Rewarding & Cat food (Fancy Feast ${ }^{\mathrm{TM}}$ chicken & 5 & $N / A$ & $N / A$ \\
\hline (consumption) & hearts and liver)* & & & \\
\hline Rewarding & Mink Lure No. 1 (Hawbaker's ${ }^{T M}$ ) & 6 & 0 & $3.6(1.7-7.9)$ \\
\hline Aversive & Mountain lion urine $* 2$ & 7 & 0 & $9.4(4.0-22.2)$ \\
\hline Ambiguous & Vanilla scent $^{2}$ & 8 & 0 & $5.9(2.5-13.7)$ \\
\hline Rewarding & $\begin{array}{l}\text { Toothbrush moved along cage } \\
\text { top by experimenter* }\end{array}$ & 9 & 0 & $1.1(0.5-2.8)$ \\
\hline Aversive & Air puff* & 10 & 2 & $1.7(0.7-4.6)$ \\
\hline $\begin{array}{l}\text { Rewarding } \\
\text { (consumption) }\end{array}$ & Hot dog sausages (diced)* & 11 & $N / A$ & $\mathrm{~N} / \mathrm{A}$ \\
\hline Ambiguous & Empty plastic bottle* & 12 & 0 & $\begin{array}{l}18.0(7.3- \\
44.5)\end{array}$ \\
\hline Rewarding & Duck liver treat (Pet Botanics & 13 & $\mathrm{~N} / \mathrm{A}$ & $\mathrm{N} / \mathrm{A}$ \\
\hline
\end{tabular}


(consumption) Healthy Omega Treats ${ }^{\mathrm{TM}}$ )

$\begin{array}{lllll}\text { Aversive } & \text { Handling glove used on farm* } & 14 & 7 & 29.8 \text { (12.3- }\end{array}$

550 * Also used in original experiment; predator odour was purchased from an online source in that

551 case, but was also urine from a wild felid (bobcat), while the candle had an "ocean" rather than

552 "linen” scent.

$553{ }^{1}$ Back-transformed from log-transformed data.

$554 \quad{ }^{2}$ Scents were presented using round absorbent cotton pads soaked with a few drops of the

555 liquid, inside a small wire mesh cage such that the mink could only touch the wire and not tear

556 the cotton.

557 
Table 2. Treatment effects in comparison with those in Meagher and Mason (2012): non-enriched relative to enriched mink Square brackets indicate a statistical trend $(0.05<p<0.10)$. NS $=$ no significant effect $(p>0.10) .---=$ not applicable because no relevant test

\begin{tabular}{|c|c|c|c|c|c|c|}
\hline \multicolumn{2}{|c|}{ Spontaneous behaviour } & \multicolumn{2}{|c|}{ Interest in stimuli } & \multirow[b]{3}{*}{ Orientation } & \multirow[b]{3}{*}{ Contact } & \multirow[b]{3}{*}{ Consumption $^{1}$} \\
\hline \multicolumn{4}{|l|}{ Loco } & & & \\
\hline stereotypy & $\begin{array}{l}\text { Lying } \\
\text { awake }\end{array}$ & Stimulus type & Latency & & & \\
\hline \multicolumn{7}{|c|}{ Original experiment } \\
\hline \multirow[t]{4}{*}{ Higher $^{2}$} & Higher $^{2}$ & All & Lower & $\begin{array}{l}\text { Higher (but } \\
\text { differs by } \\
\text { stimulus) }\end{array}$ & $\begin{array}{c}\text { Higher (but differs by } \\
\text { stimulus) }\end{array}$ & --- \\
\hline & & Aversive & Lower & NS & NS & --- \\
\hline & & Ambiguous & Lower & Higher & Higher & --- \\
\hline & & Rewarding & Lower & NS & NS & Higher \\
\hline \multicolumn{7}{|c|}{ Current replicate experiment } \\
\hline Higher & NS & All & NS & $\begin{array}{l}\text { Higher (but } \\
\text { differs by } \\
\text { stimulus) }\end{array}$ & Higher & \\
\hline
\end{tabular}




$\begin{array}{lcccc}\text { Aversive } & \text { NS } & \text { Higher } & \text { Higher } & \text {--- } \\ \text { Ambiguous } & \text { NS } & \text { Higher (but } & \text { Higher (but differs by } & \text {--- } \\ & & \text { differs by } & \text { stimulus) } \\ & \text { stimulus) } & \\ \text { Rewarding } & \text { NS } & \text { [Higher] } & \text { [Higher] }\end{array}$

\section{${ }^{1}$ Proportion of food treats consumed.}

${ }^{2}$ See Meagher et al. 2013 (here stereotypy data were for several cohorts pooled, including these individuals). 
Table 3. Interest elicited by specific stimuli in the current replicate study and the original experiment (Meagher and Mason 2012).

\begin{tabular}{|c|c|c|c|c|c|c|c|c|}
\hline \multirow[b]{4}{*}{ Category } & \multirow[b]{4}{*}{ Stimulus name } & & & & & \multirow{3}{*}{$\begin{array}{l}\text { Overall } \\
\text { interest } \\
\text { ranking² }\end{array}$} & \multirow{4}{*}{$\begin{array}{l}\text { Fear elicited? } \\
\text { (yes/no) }\end{array}$} & \multirow{4}{*}{$\begin{array}{l}\text { Effect } \\
\text { size } \\
\text { ranking } 3\end{array}$} \\
\hline & & & & & & & & \\
\hline & & \multicolumn{2}{|c|}{ Time oriented $(s)^{1}$} & \multicolumn{2}{|c|}{ Time in contact $(s)^{1}$} & & & \\
\hline & & NE & $\mathbf{E}$ & NE & $\mathbf{E}$ & & & \\
\hline \multicolumn{9}{|c|}{ Original experiment (Meagher and Mason 2012) } \\
\hline Rewarding & Brush & 274.9 & 272.0 & 226.1 & 220.0 & 1 & Yes & 9.5 \\
\hline Aversive & Predator odour & 210.1 & 178.8 & 196.4 & 162.4 & 2 & Yes & 6.5 \\
\hline Aversive & Air puff & 178.5 & 163.5 & 125.1 & 106.2 & 3 & Yes & 8 \\
\hline Neutral & Bottle & 203.6 & 141.9 & 163.0 & 101.3 & 4.5 & Yes & 4.5 \\
\hline Neutral & Maraca & 213.8 & 151.3 & 153.2 & 91.1 & 4.5 & No & 3 \\
\hline Aversive & Predator silhouette & 161.6 & 130.8 & $\mathrm{n} / \mathrm{a}$ & $\mathrm{n} / \mathrm{a}$ & 6 & Yes & 8 \\
\hline Rewarding & Faeces & 183.1 & 102.8 & 172.5 & 88.0 & 7 & No & 2 \\
\hline Aversive & Glove & 173.4 & 121.9 & 72.1 & 56.6 & 8 & Yes & 7 \\
\hline Neutral & Peppermint & 186.7 & 94.2 & 117.1 & 57.8 & 8.5 & No & 3.5 \\
\hline
\end{tabular}




\begin{tabular}{|c|c|c|c|c|c|c|c|c|}
\hline Neutral & Scented candle & 185.1 & 85.1 & 125.4 & 63.4 & 8.5 & No & 2 \\
\hline \multicolumn{9}{|c|}{ Replicate (current) experiment } \\
\hline Aversive & Air & 158.0 & 200.8 & 124.0 & 188.0 & 2.5 & Yes & 7.5 \\
\hline Neutral & Bottle & 68.3 & 184.8 & 60.0 & 149.0 & 5 & No & 3.5 \\
\hline Neutral & Candle & 83.8 & 69.8 & 59.0 & 40.7 & 11 & No & 11 \\
\hline Neutral & Dog toy & 113.8 & 216.8 & 87.0 & 169.0 & 4 & No & 5 \\
\hline Aversive & Glove & 127.6 & 114.8 & 0.0 & 46.7 & 7.5 & Yes & 9.5 \\
\hline Rewarding & Mink lure & 81.5 & 160.5 & 61.0 & 122.7 & 7 & No & 7.5 \\
\hline Aversive & Mountain lion urine & 64.0 & 164.5 & 49.7 & 155.0 & 7 & No & 3.5 \\
\hline Rewarding & Pheasant scent & 110.8 & 253.0 & 65.0 & 221.0 & 2.5 & Yes & 1 \\
\hline Aversive & Polar bear urine & 55.3 & 152.0 & 40.0 & 136.3 & 8.5 & No & 4.5 \\
\hline Rewarding & Toothbrush & 294.0 & 295.0 & 277.7 & 281.0 & 1 & No & 9.5 \\
\hline Neutral & Vanilla & 24.0 & 136.8 & 16.0 & 110.3 & 10 & No & 3.5 \\
\hline
\end{tabular}

\footnotetext{
${ }^{1}$ Values are least squares means from general linear models (original experiment) and from MANOVAs for the replicate.

${ }^{2}$ Ranked within each measure of exploration (orientation and contact), then given overall ranking by averaging the two, with the highest rank (smallest number) indicating the highest durations.
} 
${ }^{3}$ Ranked within each variable (orientation and contact), then given overall ranking by averaging the two, with the highest rank (smallest number) indicating the largest difference between treatment means (non-enriched minus enriched) 
Table 4. Correlations between interest in stimuli and other behaviour patterns hypothesized to reflect boredom. Original =

original experiment (Meagher and Mason 2012), replicate = current experiment. NS = no significant effect $(p>0.10)$.

Square brackets indicate a statistical trend $(0.05<p<0.10)$; these treatment-specific effects are reported where there was a

significant interaction between treatment and behaviour. Neg. $=$ negative relationship, pos. $=$ positive. $---=$ not applicable because no relevant test

\section{Stimulus type}

\begin{tabular}{|c|c|c|c|c|c|c|c|c|}
\hline \multirow[t]{2}{*}{ Measure } & \multicolumn{2}{|c|}{ All } & \multicolumn{2}{|c|}{ Aversive } & \multicolumn{2}{|c|}{ Ambiguous } & \multicolumn{2}{|c|}{ Rewarding } \\
\hline & Original & Replicate & Original & Replicate & Original & Replicate & Original & Replicate \\
\hline \multicolumn{9}{|l|}{ Lying still but awake } \\
\hline Latency & Neg. & NS & NS & NS & NS & NS & Neg. & Neg. \\
\hline Duration oriented & $\begin{array}{l}\text { [E only, } \\
\text { pos.] }\end{array}$ & $\begin{array}{l}\text { E only, } \\
\text { pos. }\end{array}$ & NS & $\begin{array}{l}\text { E only, } \\
\text { pos. }\end{array}$ & $\begin{array}{l}\text { [E only, } \\
\text { pos.] }\end{array}$ & NS & NS & NS \\
\hline Duration in contact & NS & $\begin{array}{l}\text { E only, } \\
\text { pos. }\end{array}$ & NS & $\begin{array}{l}\text { E only, } \\
\text { pos. }\end{array}$ & NS & $\begin{array}{l}\text { E only, } \\
\text { pos. }\end{array}$ & NS & NS \\
\hline Treat consumption & --- & & --- & & --- & & $\begin{array}{l}\text { [E only, } \\
\text { pos.] }\end{array}$ & NS \\
\hline
\end{tabular}


Loco stereotypic behaviour

\begin{tabular}{|c|c|c|c|c|c|c|c|c|}
\hline Latency & NS & NS & NS & NS & NS & NS & NS & NS \\
\hline Duration oriented & $\begin{array}{l}\text { Interaction } \\
\text { but each } \\
\text { treatment } \\
\text { NS }\end{array}$ & NS & $\begin{array}{l}\text { [E only, } \\
\text { neg.] }\end{array}$ & NS & NS & NS & Neg. & NS \\
\hline Duration in contact & $\begin{array}{l}\text { [E only, } \\
\text { neg.] }\end{array}$ & NS & $\begin{array}{l}\text { E only, } \\
\text { neg. }\end{array}$ & NS & NS & NS & Neg. & NS \\
\hline Treat consumption & --- & & --- & & --- & & & NS \\
\hline
\end{tabular}


9. Figure captions

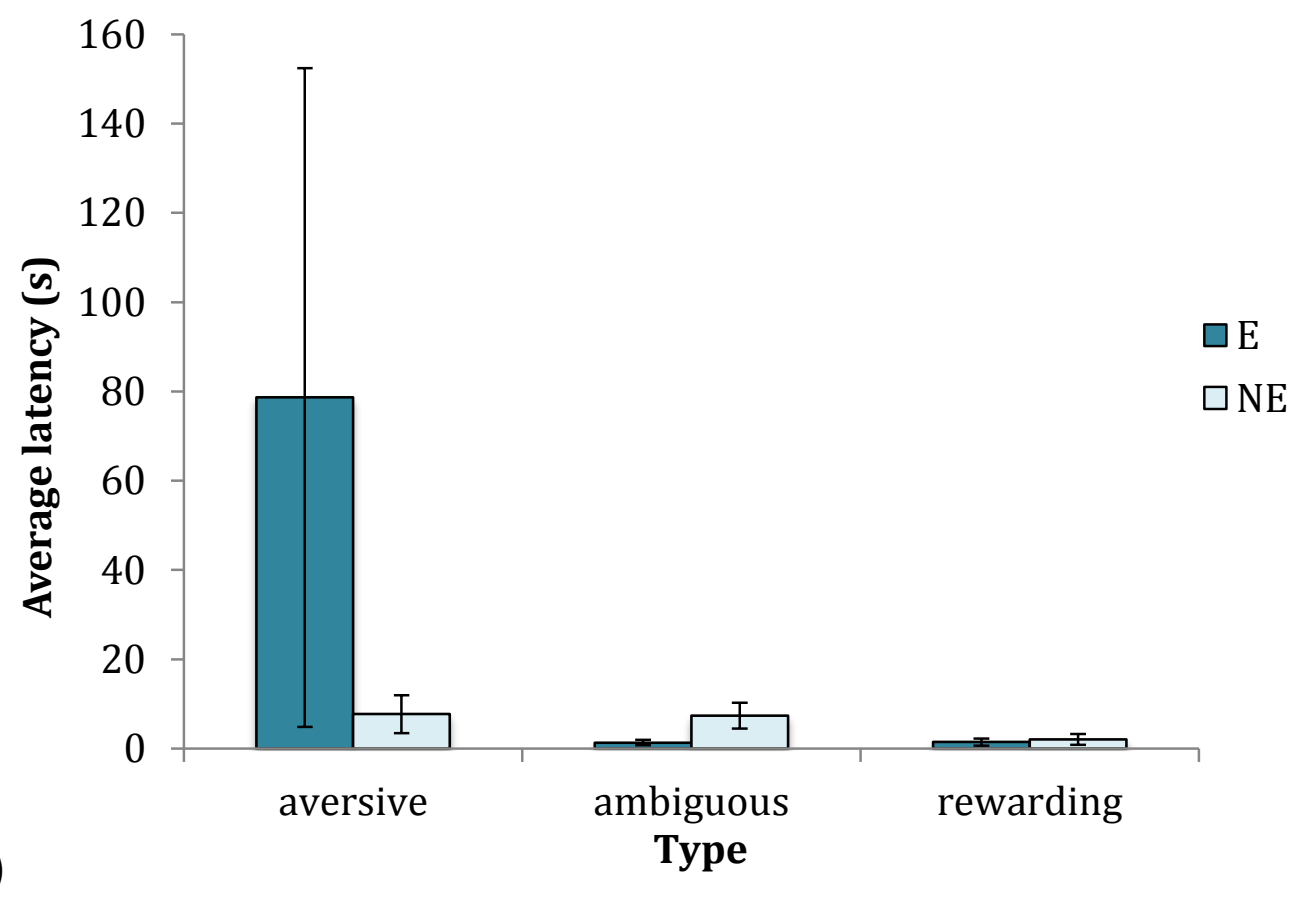




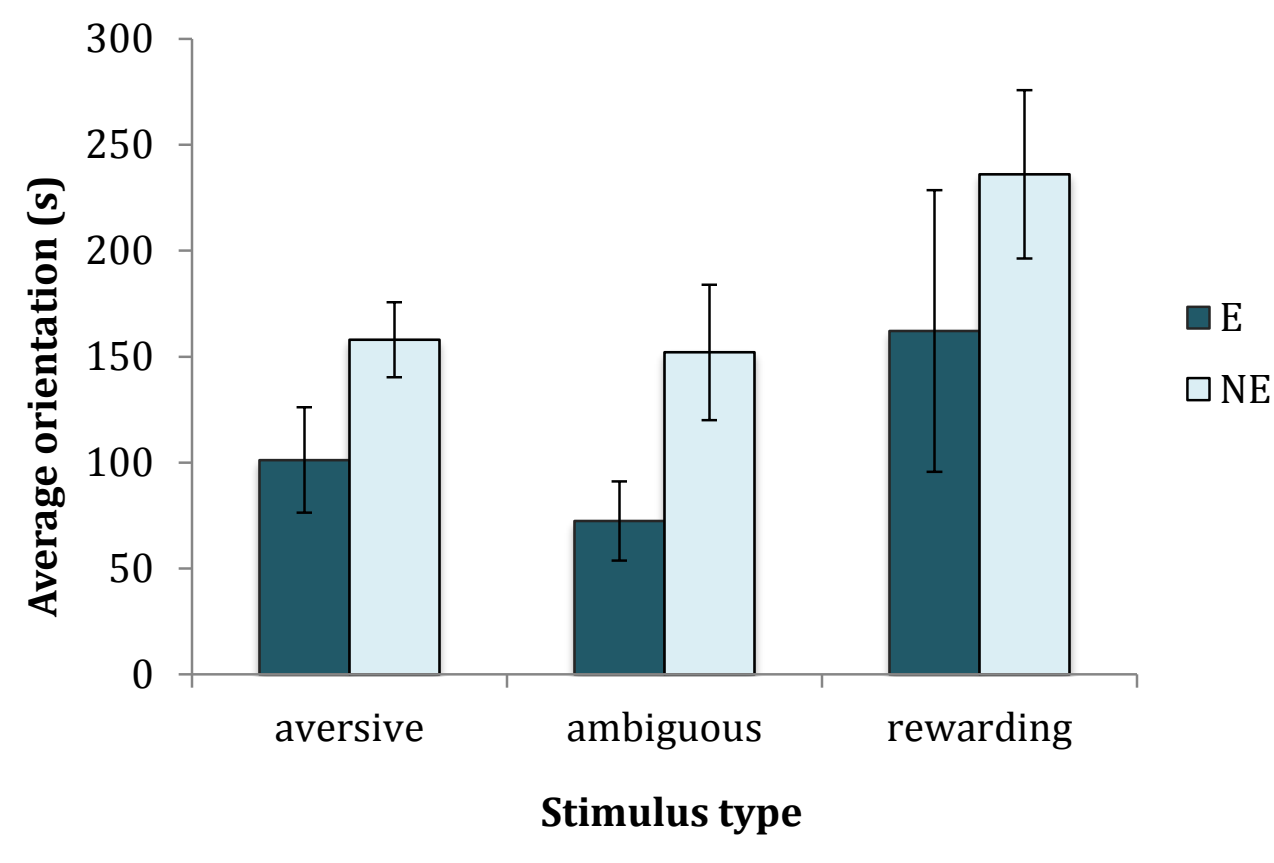




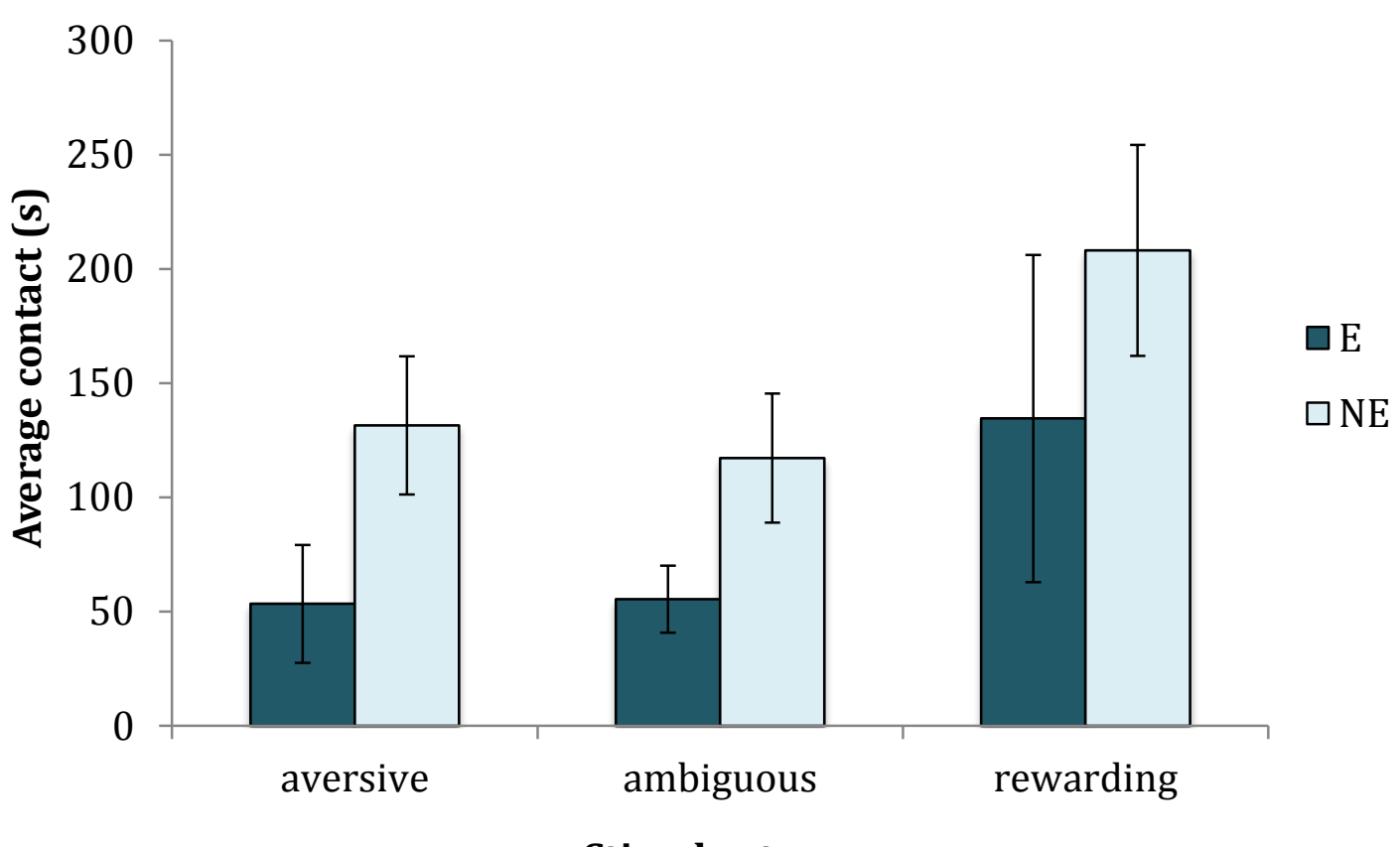

c)

\section{Stimulus type}

Figure 1. Minks' interest in stimuli by housing treatment and stimulus type. a) Latency to contact (back-transformed from log data);

b) average duration oriented to stimulus over 10 minute tests; c) average duration in contact with stimulus. Values are averages of least square means for each stimulus within the categories $\pm \mathrm{SE}$. 


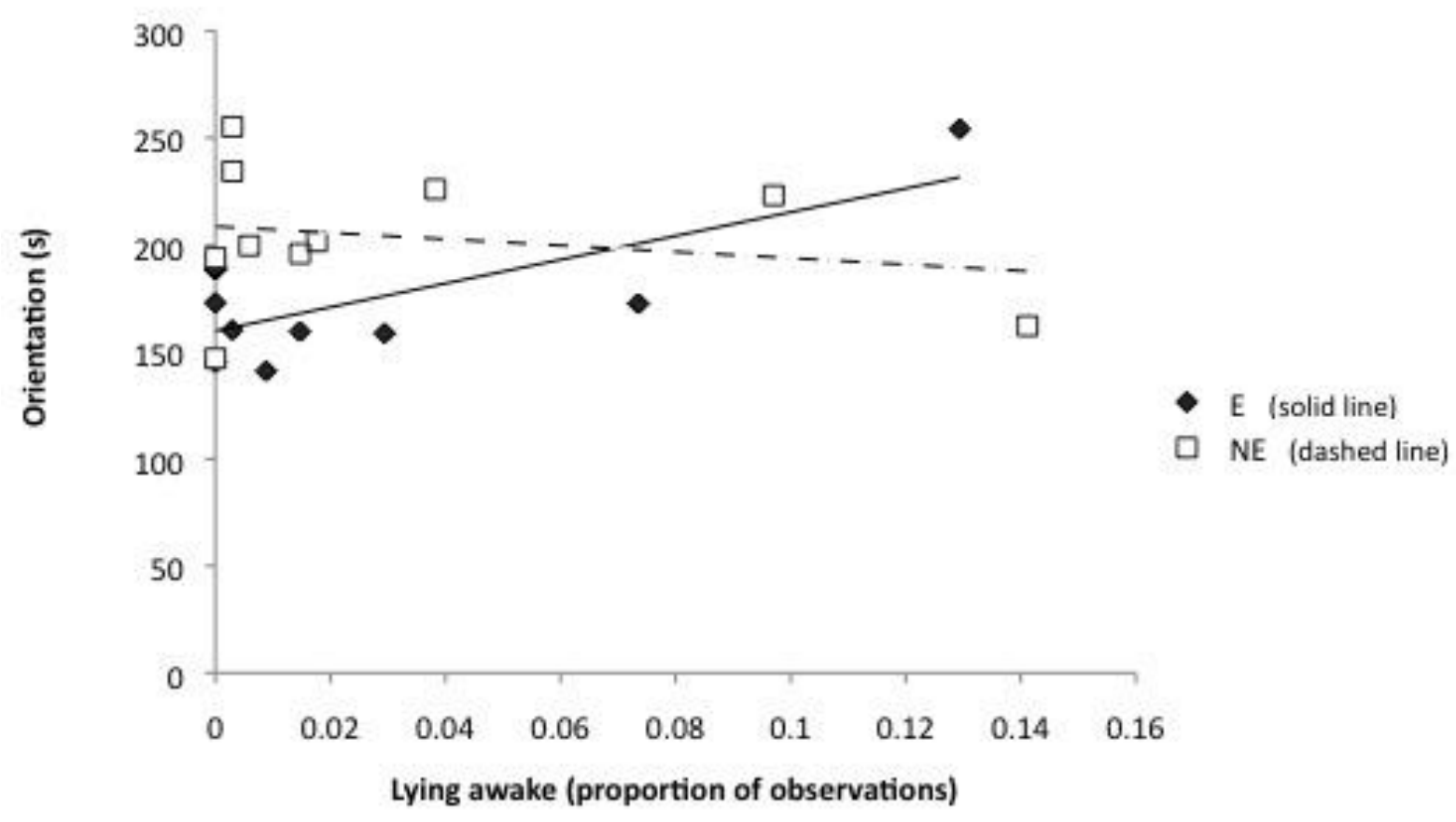

Figure 2. The duration of time mink spent oriented to all stimuli presented in the tests, regressed against the time spent lying still but awake in the home cage during scanning observations over the winter (split by housing treatment). Values on the $y$-axis are least squares means. 


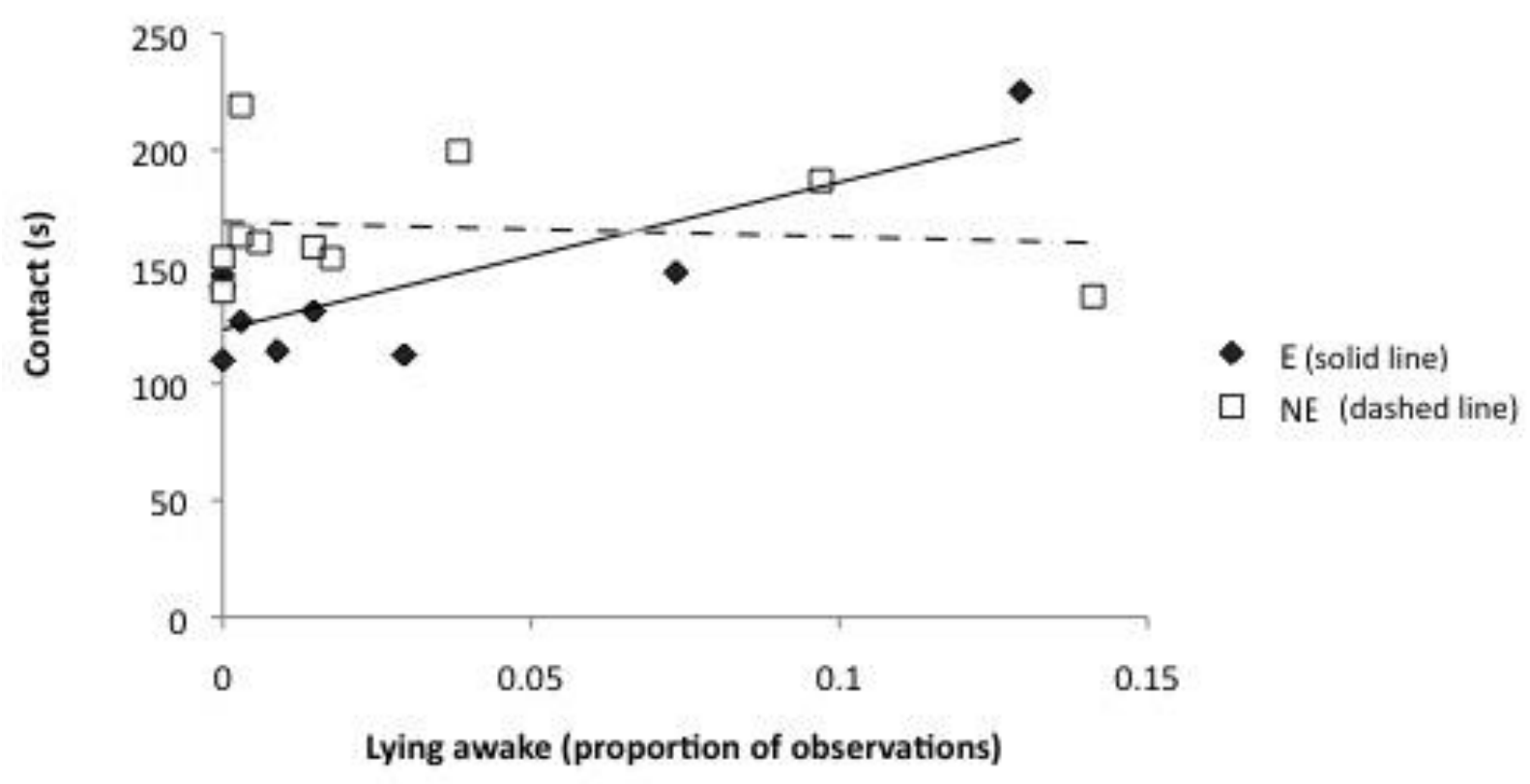

Figure 3. The duration of time mink spent in contact with all stimuli, regressed against time spent lying still but awake (split by housing treatment). Values on the $y$-axis are least squares means. 